\title{
Happiness is greater in natural environments
}

\author{
George MacKerron ${ }^{\mathrm{a}, \mathrm{b}, *}$, Susana Mourato ${ }^{\mathrm{b}, \mathrm{c}}$ \\ ${ }^{a}$ Centre for Advanced Spatial Analysis, University College London, Gower Street, London W1T 4TG, UK \\ ${ }^{b}$ Grantham Research Institute on Climate Change \& the Environment, London School of Economics \& Political Science (LSE), Houghton \\ Street, London WC2A $2 A E$, UK \\ ${ }^{c}$ Department of Geography \& Environment, LSE
}

\begin{abstract}
Background Links between wellbeing and environmental factors are of interest in health, psychology, economics, and more widely. There is some evidence, albeit limited, that green or natural environments are positive for physical and mental health and wellbeing. We present a new and unique primary research study exploring the relationship between momentary subjective wellbeing (SWB) and individuals' immediate environment within the UK.

Methods We developed and applied an innovative data collection tool: a smartphone app that signals participants at random moments, presenting a brief questionnaire while using satellite positioning (GPS) to determine geographical coordinates. We used this to collect over one million responses from more than 20,000 participants. Associating GPS response locations with objective spatial data, we estimate a model relating land cover to SWB using only the within-individual variation, while controlling for weather, daylight, activity, companionship, location type, time, day, and any response trend.

Findings On average, study participants are significantly and substantially happier outdoors in all green or natural habitat types than they are in urban environments. These findings are robust to a number of alternative models and model specifications.

Interpretation This study provides a new line of evidence on links between nature and wellbeing, strengthening existing evidence of a positive relationship between SWB and exposure to green or natural environments in daily life. The novel geo-located experience sampling methodology we describe has great potential to provide new insights in psychology, health, and beyond.
\end{abstract}

Funding Economic and Social Research Council (grant number PTA-031-2006-00280), UK.

\section{Introduction}

There are at least three reasons for thinking that experiences of natural environments will be positively related to health, wellbeing and happiness. First, there appear to be direct pathways by which such experiences affect the nervous system, bringing about stress reduction and restoration of attention (the existence of such pathways - biophilia - has plausible evolutionary explanations). ${ }^{1}$ Second, natural environments may be lower in environmental 'bads' that have significant negative impacts on physical and mental wellbeing, such as air pollutants and noise. Third, natural environments may encourage behaviours that are physically and mentally beneficial, including physical exercise, recreation and social interaction. ${ }^{2}$

Researchers have pursued both observational and experimental evidence on this link. Observational studies have related averaged wellbeing measures to aggregate environmental characteristics between geographical regions. ${ }^{3-5}$ They have also compared individuals' SWB reports or medical records with the proximity of their homes to natural environments, or with alternative indicators of local environmental quality ${ }^{6-10}$ Experimental and quasiexperimental studies have investigated physiological and psychological effects of exposure to images of different environment types ${ }^{11,12}$ or to short-term interventions bringing subjects into contact with nature. ${ }^{13-15}$ They have

\footnotetext{
${ }^{*}$ Corresponding author.

Email addresses: g. macker ron@ucl . ac.uk (George MacKerron), s.mourato@l se . ac . uk (Susana Mourato)
} 
also related health outcomes or frequency of healthcare-seeking behaviour to views of nature in controlled institutional settings. ${ }^{16,17}$

Most such studies report beneficial impacts of natural environments on health or wellbeing, but they have some common weaknesses. Observational studies measure domestic proximity to natural environments but not actual experiences of such environments (which may not occur near home, and may occur elsewhere); cannot provide data on the moment-by-moment hedonic or affective element of wellbeing; and are reliant on retrospective assessments that are subject to substantial recall bias. ${ }^{18}$ Experimental studies are stronger in these respects but, by their nature, have lesser ecological validity — that is, they tell us a limited amount about people's real experiences of natural environments in their everyday lives.

Longitudinal study designs in which participants provide ongoing reports of their everyday experience - Ecological Momentary Assessment (EMA) ${ }^{19}$, the Experience Sampling Method (ESM), ${ }^{20}$ and the Day Reconstruction Method (DRM) ${ }^{21}$ — provide some of the best evidence regarding influences on wellbeing in general. However, these methods have conventionally been cumbersome, expensive, and limited to very small samples. ${ }^{22}$ They have also been unable to provide objective location data. For these reasons, such ongoing assessment methods have not previously been applied to the study of wellbeing in different environments.

We have addressed these shortcomings — and the concomitant lack of ongoing assessment data regarding wellbeing and environment — in a pioneering, large-scale ESM study.

\section{Methods}

We developed a native software application (app) named Mappiness for the Apple iPhone. The app is distributed via the App Store, a central software repository accessible to all device users. Participants are recruited opportunistically, assisted by coverage in traditional and social media.

Prospective participants download the app at no charge, indicate their informed consent to taking part, and provide basic demographic information. They are then signalled at random moments, with a frequency and during hours they choose (the defaults are twice a day between 08.00 and 22.00) and asked to report the extent to which they are feeling 'Happy' on a continuous sliding scale. Participants are also asked whom they are with, where they are, and what they are doing (the full questionnaire is reproduced in the Supplementary Information, and example screens are shown in Figure S1 there). While they answer, precise location is determined by GPS. The encrypted data is then transmitted to our server. Participants receive simple feedback, charting their happiness in different contexts, and can take part for as long or short a period as they wish.

We associate each response with three key spatial and environmental indicators using the GPS location data. We calculate the habitat type at each reported point location using the 25m-resolution UK Land Cover Map 2000 (LCM), ${ }^{23}$ grouping LCM subclasses into the same nine broad habitat categories used in the UK National Ecosystem Assessment $^{24}$ (the categories are as listed in Table 1, and their composition is provided in Table S1 in the Supplementary Information). Using data from Weather Underground, which collates data from 280 weather sensors across the UK, we link each response with weather conditions reported by the station nearest the response location at the moment nearest the response timestamp. We also calculate whether it was daylight at the response date, time and location.

We use our data to estimate a fixed effects model of happiness self-ratings. This model has participant-specific intercepts - the fixed effects - and is equivalent to an OLS regression in which a dummy variable is included for each participant. The fixed effects soak up all time-invariant individual-specific characteristics, including personality characteristics and demographic variables such as age and income.

On the left hand side of our model, the happiness self-rating is scaled from 0 ('Not at all') to 100 ('Extremely'). On the right hand side we include dummies for habitat types when outdoors, which are the focus of this research. However, experience of different environments may well be associated with other variables that are important to wellbeing. For example, visits to parks could be correlated with the presence of family and friends, leisure activities, weekends, and good weather. We therefore include as control variables the indicators of daylight and weather conditions when outdoors, activity, companionship, location type, and time of day (separately for Monday - Friday and Saturday - Sunday). We also include response sequence indicators, capturing the number of previous responses by the same participant, to control for possible trends in happiness (or response behaviour) over time.

We use responses received between mid-August 2010 and mid-February 2011 that are valid according to three criteria. First, they must be prompted by a signal: we identify such responses as those starting within 60 minutes of a previously unanswered signal, and completed within a further 5 minutes. Second, they must have a UK GPS 
location for which, if outdoors, the device-reported accuracy is $+/-250 \mathrm{~m}$ or better. Third, local weather data must be available for within 3 hours of the response time. Descriptive statistics are reported for these valid responses and their contributing participants only.

\section{Results}

Our analysis is based on 1,138,481 valid responses from 21,947 participants. We believe these sample sizes to be the largest ever achieved by an ESM study. Our reliance on participants' own mobile devices restricts the sample's demographic profile, however. Participants are relatively wealthy: median household income is approximately GBP $£ 48,000$, almost twice the UK median. ${ }^{25}$ They are also relatively young: $66 \%$ are aged under 35 , and $95 \%$ under 50 , compared to $29 \%$ and $56 \%$ respectively in the UK adult population. ${ }^{26} 78 \%$ of participants are in employment and $13 \%$ are in full-time education. These groups are over-represented relative to the UK adult population, in which the proportions are respectively $57 \%$ and $4 \%$, primarily at the expense of retired people, who constitute $0.5 \%$ of participants but $22 \%$ of the population. ${ }^{27}$ Participants' sex ratio is nearly balanced, at $55 \%$ male, compared to $49 \%$ in the UK adult population. ${ }^{26}$

The number of responses per participant ranges from 1 to 737 (mean 51.9). 14\% of participants were still actively responding when the data set was extracted, so this parameter is not the same as participants' final response count. Responses come from across the UK but are concentrated around population centres, as shown in Figure 1. As in any signal-contingent ESM study, necessary conditions for receiving a valid response include that the signalled participant is: in possession of the powered-on signalling device; in an area with wireless data reception (e.g. not on an underground rail system); able to hear the signal (e.g. not in a noisy club); able to respond (e.g. not driving); and willing to do so. These requirements inevitably restrict the sample of experiences captured. In total, amongst participants who contributed at least one valid response, $48 \%$ of signals resulted in a valid response.

All explanatory variables in our analysis are 0/1 dummies. They are summarised in Table 1 . The happiness response, scaled $0-100$, has a mean of 66.4 and standard deviation of 21.6: as is typical for SWB parameters, its distribution is negatively skewed. The distribution, which is illustrated in Figure 2, also shows two artefacts of the response process: spikes at the absolute extremes of the distribution, where the response slider is moved to its limit, and small troughs on either side of the midpoint, where the response slider is most commonly either left in its initial position or moved a minimum distance to the left or right. We check the robustness of our results to excluding the spikes at the extremes.

\section{Fixed effects model}

Table 2 presents the model. All control variables show relationships with the happiness score that are intuitive and (where applicable) in line with previous research. For example, participants are happier at home than at work, and greater happiness is also associated with higher temperatures and lower wind speeds, with sunshine, and with the absence of rain and fog. Physical activities, and activities expected to be common in natural environments (such as running, gardening or birdwatching), also show substantial positive associations with happiness. Participants are happier outdoors than indoors or in a vehicle.

When outdoors, every habitat type except inland bare ground is associated with significantly higher happiness levels than the continuous urban type. Coastal locations are by some distance the happiest, with responses approximately 6 points higher than continuous urban environments on the $0-100$ scale. Alternatively expressed, this is a difference of $0 \cdot 28$ standard deviations, or one of similar magnitude to, for instance, the difference between attending an exhibition and doing housework.

All other green or natural environment types — 'mountains, moors, and heathlands', 'freshwater, wetlands and flood plains', woodland, grasslands, and farmland — are between 2.7 and 1.8 points happier than continuous urban environments. Suburban or rural developed environments are a little under one point happier.

\section{Scenarios}

Certain activities, such as gardening, birdwatching, hunting and fishing, may be mainly or exclusively carried on outdoors and in natural environments. And, of course, people may be more likely to spend time in natural environments in pleasant weather. Assuming, of course, that our model is correctly specified in its inclusion of these variables as independent effects, we may simply add coefficients together to predict happiness levels in specific scenarios. Thus, for example, the predicted happiness of a person who is outdoors $(+2 \cdot 32)$, birdwatching 


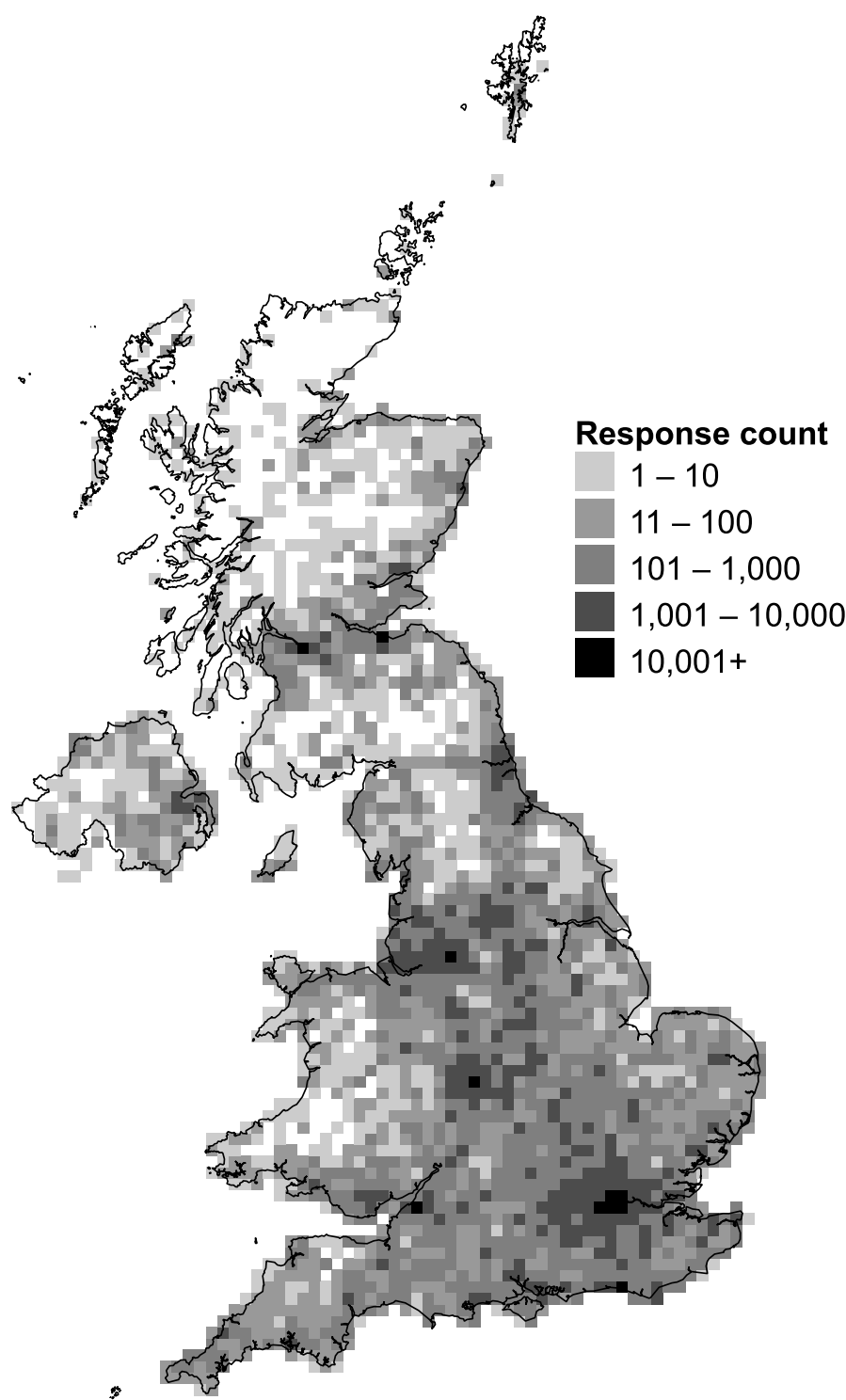

Outline represents UK. This work is based on data provided through EDINA UKBORDERS with the support of the ESRC and JISC and uses boundary material which is copyright of the Crown and the Post Office. Source for N. Ireland boundary: 2001 Census, Output Area Boundaries. Crown copyright 2003. Crown copyright material is reproduced with the permission of the Controller of HMSO.

Figure 1: Response coverage, shown as response count per 10km cell and shaded logarithmically. 
Table 1: Descriptive statistics for explanatory variables. All variables are $0 / 1$ dummies. All percentages — including where variables are interacted with the variable 'Outdoors' - are calculated in relation to the full sample of 1,138,481 responses.

\begin{tabular}{lrr}
\hline Variable & $\%$ & Count \\
\hline Participant is... & & \\
\hline Indoors & $85 \cdot 41$ & 972,398 \\
\hline In a vehicle & $7 \cdot 11$ & 80,981 \\
\hline Outdoors & 7.48 & 85,102 \\
\hline
\end{tabular}

Land cover type when participant is outdoors

\begin{tabular}{lcr}
\hline Marine and coastal margins & $0 \cdot 06$ & 735 \\
\hline Freshwater, wetlands and flood plains & $0 \cdot 06$ & 668 \\
\hline Mountains, moors and heathland & $0 \cdot 04$ & 410 \\
\hline Semi-natural grasslands & $0 \cdot 34$ & 3,910 \\
\hline Enclosed farmland & $0 \cdot 81$ & 9,235 \\
\hline Coniferous woodland & $0 \cdot 04$ & 501 \\
\hline Broad-leaved/mixed woodland & $0 \cdot 25$ & 2,822 \\
\hline Inland bare ground & $0 \cdot 14$ & 1,630 \\
\hline Suburban/rural developed & 1.94 & 22,119 \\
\hline Continuous urban & $3 \cdot 78$ & 43,072
\end{tabular}

Weather when participant is outdoors

\begin{tabular}{lrr}
\hline Daylight & $6 \cdot 06$ & 69,015 \\
\hline Sun & $0 \cdot 91$ & 10,321 \\
\hline Rain & $0 \cdot 65$ & 7,441 \\
\hline Snow & $0 \cdot 05$ & 589 \\
\hline Fog & $0 \cdot 11$ & 1,236 \\
\hline$<0{ }^{\circ} \mathrm{C}$ & $0 \cdot 19$ & 2,193 \\
\hline $0-<8{ }^{\circ} \mathrm{C}$ & $1 \cdot 15$ & 13,130 \\
\hline $8-<16^{\circ} \mathrm{C}$ & $2 \cdot 90$ & 32,961 \\
\hline $16-<24{ }^{\circ} \mathrm{C}$ & $3 \cdot 22$ & 36,636 \\
\hline $24+{ }^{\circ} \mathrm{C}$ & $0 \cdot 02$ & 182 \\
\hline $0-<5 \mathrm{~km} / \mathrm{h}$ windspeed & $1 \cdot 06$ & 12,064 \\
\hline $5-<15 \mathrm{~km} / \mathrm{h}$ windspeed & $3 \cdot 02$ & 34,378 \\
\hline $15-<25 \mathrm{~km} / \mathrm{h}$ windspeed & $2 \cdot 52$ & 28,746 \\
\hline $25+\mathrm{km} / \mathrm{h} \mathrm{windspeed}$ & $0 \cdot 87$ & 9,914 \\
\hline
\end{tabular}

\begin{tabular}{llll}
\hline Variable & $\%$ & Count \\
\hline
\end{tabular}

Selected activities

\begin{tabular}{lrr}
\hline Walking, hiking & 1.22 & 13,847 \\
\hline Sports, running, exercise & 1.02 & 11,653 \\
\hline Gardening, allotment & $0 \cdot 20$ & 2,305 \\
\hline Bird watching, nature watching & 0.06 & 695 \\
\hline Hunting, fishing & 0.03 & 293 \\
\hline
\end{tabular}

Participant is with...

\begin{tabular}{lrr}
\hline Spouse, partner, girl/boyfriend & $24 \cdot 34$ & 277,073 \\
\hline Children & $10 \cdot 68$ & 121,555 \\
\hline Other family members & 8.50 & 96,814 \\
\hline Colleagues, classmates & 17.98 & 204,697 \\
\hline Clients, customers & 1.63 & 18,510 \\
\hline Friends & 9.63 & 109,627 \\
\hline Other people participant knows & 1.64 & 18,624 \\
\hline Nobody (or strangers only) & 40.42 & 460,158 \\
\hline
\end{tabular}

Participant is...

\begin{tabular}{lll}
\hline At home & $50 \cdot 97$ & 580,269 \\
\hline At work & $24 \cdot 53$ & 279,242 \\
\hline Elsewhere & $24 \cdot 50$ & 278,970 \\
\hline
\end{tabular}




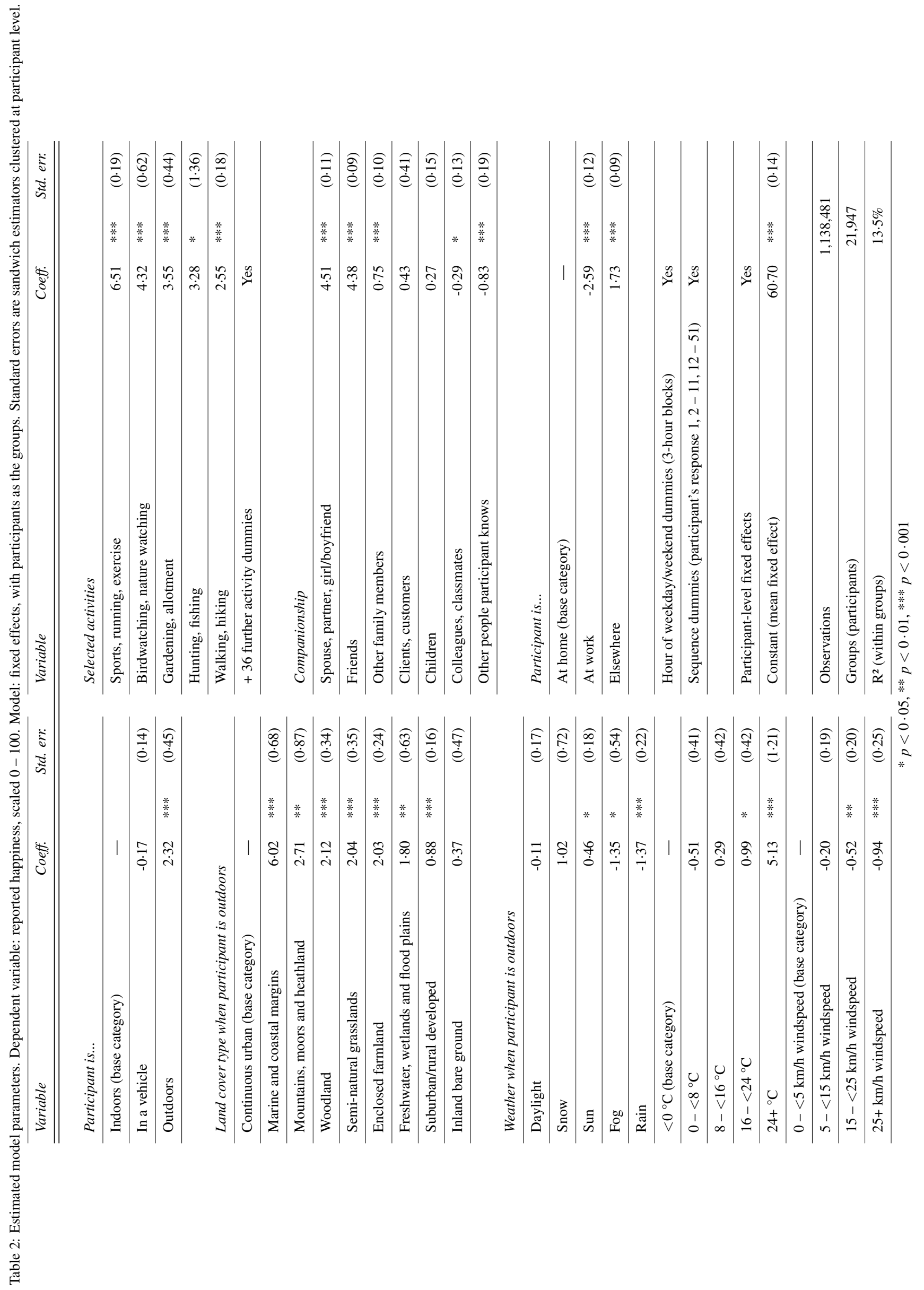




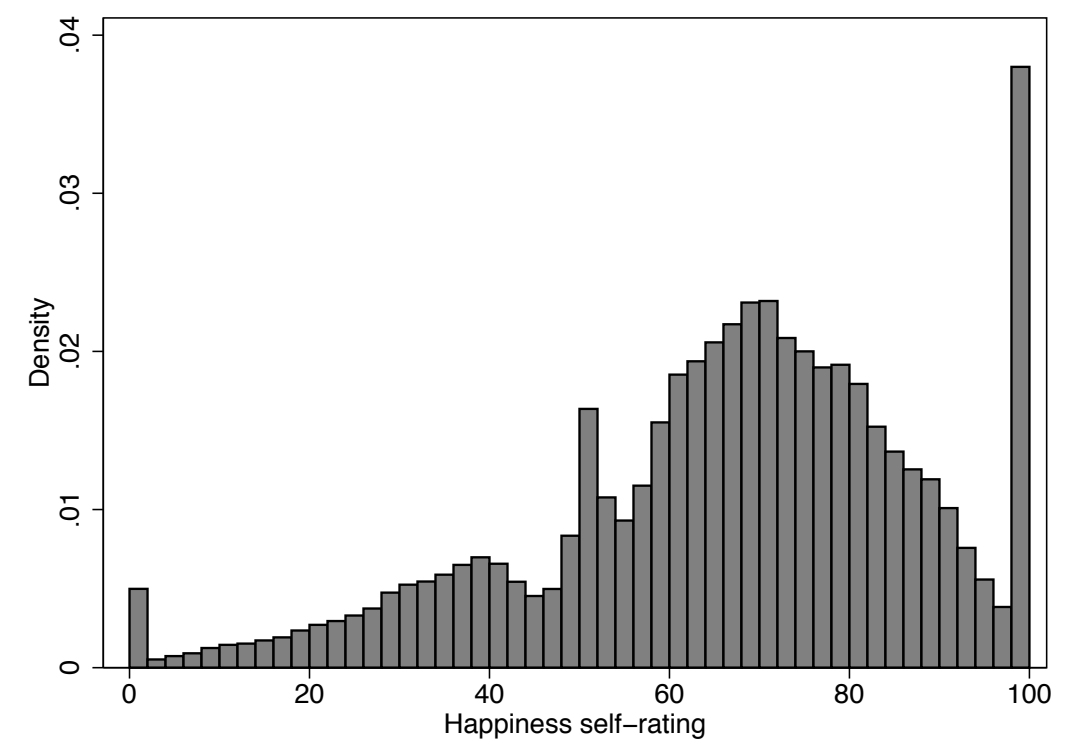

Figure 2: Distribution of happiness self-ratings

$(+4 \cdot 32)$ with friends $(+4 \cdot 38)$, in heathland $(+2 \cdot 71)$, on a hot $(+5 \cdot 13)$ and sunny $(+0 \cdot 46)$ Sunday early afternoon $(+4 \cdot 30)$ is approximately 26 scale points (or 1.2 standard deviations) higher than that of someone who is commuting $(-2 \cdot 03)$, on his or her own, in a city, in a vehicle, on a cold, grey, early weekday morning. Equivalently, this is a difference of about the same size as between being ill in bed $(-19.65)$ versus doing physical exercise $(+6 \cdot 51)$, keeping all other factors the same.

\section{Robustness checks}

We have performed a number of robustness checks on our results.

As an alternative approach to identifying high-quality natural environments, we re-ran the model replacing the LCM habitat variables with three (in some cases overlapping) indicators of UK landscape designations. The designated areas were: Areas of Outstanding Natural Beauty (AONB — including the Scottish equivalent, National Scenic Areas), with 2,462 outdoor responses; National Parks (NP), with 1,402 outdoor responses; and National Nature Reserves (NNR), with 117 outdoor responses. All three designations were positively and significantly related to happiness ratings (AONB coeff. 2·39, std. err. 0.55, $p<0 \cdot 0001$; NP coeff. 4.59, std. err. 0.58, $p<$ $0 \cdot 0001 ;$ NNR coeff. 5.00, std. err. $1 \cdot 62, p=0 \cdot 0020)$.

We tested the effect of imposing more stringent response validity criteria, requiring responses to be made within 20 minutes of a signal instead of 60 minutes, and reported accuracy to be $100 \mathrm{~m}$ or better instead of $250 \mathrm{~m}$. These criteria reduce the response sample size by just under half. The sign and significance of all LCM habitat variable coefficients are unchanged in this regression relative to that reported in Table 2, and no coefficient varies by more than 0.5 between the two.

We ran an interval regression model accounting for the truncation of happiness ratings at either extreme of the scale $(10,582$ responses at zero and 80,994 at 100), seen as the spikes in Figure 2. We do not use this as our main model because fixed effects cannot be included. However, in this model all natural land cover coefficients are slightly increased in magnitude, and all remain highly significant.

Though we include a wide range of control variables in our happiness model, we do not ask whether participants are on holiday. If participants are more likely to visit remote, high-EQ environments when on holiday, then it is possible that happiness effects we have attributed to natural environments are actually due, in whole or in part, to enjoyment of such leisure time. To address this issue we re-estimated the model using only responses received on weekends and public holidays, when the great majority of respondents are 'on vacation' in the sense that they are free to engage in leisure activities. This restriction reduces the response sample size by about twothirds. All LCM type coefficients remain positive. Coefficients on all green and blue space types are reduced somewhat in magnitude, however, and those on the 'mountains, moors, and heathlands' and 'freshwater, wetlands, and floodplains' types are no longer significantly different from zero at the $5 \%$ level. 
Finally, meaningful hypothesis testing requires that the significance level be a decreasing function of sample size, ${ }^{28}$ and our sample size is very large. In addition, in interpreting our coefficients of interest, we are making multiple comparisons. We can account for the first issue by using the natural log of the sample size as a higher-than-usual critical $F$ value ${ }^{29}$ when testing whether each coefficient is different from zero. We can account for the second using the Bonferroni correction, dividing the significance threshold $(p<0 \cdot 05)$ by the number of tests. ${ }^{30}$ Coefficients on all green or natural land cover types except two — again, the mountain and freshwater environment types — retain significance even using the substantially more stringent thresholds calculated using these procedures.

\section{Discussion}

This study provides a new line of evidence on the links between nature and human wellbeing. Amongst study participants, happiness is greater in natural environments, even after controlling for a wide range of potential confounders.

Our sample is limited to iPhone users, and we cannot be certain that identical results would be obtained for the UK population as a whole. On the other hand, we know of no compelling reason to suppose that the association between happiness and environment will differ markedly within and outside of our sample.

The relationships we estimate are highly statistically significant, and their magnitudes are substantial. We know that the relationships are not confounded at the participant level (that is, by associations between types of locations and types of people), because our model is estimated exclusively from within-individual variation. And we have controlled for a reasonably comprehensive set of potential confounders at the response level.

Causal pathways may run in both directions, such that people choose an environment partly according to their mood, and people's moods are partly determined by their environment. It seems highly plausible that the latter pathway makes an important contribution to the relationship, and future research using this data will address this in greater detail.

In our view there is enormous potential for the geo-located experience sampling methodology we have described to provide further insights in psychology, health, and beyond. It enables ESM/EMA to be applied on a very large scale, enabling the impacts of public health interventions (such as green exercise, obesity reduction or smoking cessation programmes) to be comprehensively assessed both across geographical areas and over time. It can also shed light on whether such interventions are more beneficial in certain types of surroundings - for example, whether there is any difference in wellbeing from a programme that keeps participants active outdoors rather than in the gym.

Ongoing geo-located experience sampling studies, including Mappiness, can also be used to measure wellbeing impacts of unfavourable events (such as epidemics or incidents of water contamination, air pollution or terrorism). Studies could be developed more specifically to investigate individuals' resilience in the face of such adversity, allowing research on the factors mediating relationships between day-to-day fluctuations in wellbeing and positive and negative events. Finally, these methods could augment emerging locally-based natural resource monitoring efforts in developing countries. Using similar apps on GPS-enabled devices, local populations could not only collect real-time information on ecological change (such as water pollution and/or scarcity, forest disturbance, reef destruction, and wildlife population decline), but simultaneously also help gauge the associated consequences for physical and mental health.

\section{Author contributions}

G.M. conceived of the research, implemented the software, analysed the data, and co-wrote the paper. S.M. supervised the research and contributed to the model specification and the writing of the paper.

\section{Conflicts of interest}

We declare that we have no conflicts of interest.

\section{Acknowledgements}

We thank: Steve Gibbons, Jouni Kuha, Raphael Calel, Antoine Dechezleprêtre, and Rich Aston; all beta testers of the iPhone app; and all Mappiness study participants. 
References

[1] Wilson EO (1993) in The Biophilia Hypothesis, eds Kellert SR, Wilson EO (Island Press, Washington DC), pp 31-41.

[2] Barton J, Pretty J (2010) in Urban Ecology, ed Gaston K (Cambridge University Press), pp 202-229.

[3] Mitchell R, Popham F (2007) Greenspace, urbanity and health: Relationships in England. Journal of Epidemiology and Community Health 61:681-683.

[4] Vemuri AW, Costanza R (2006) The role of human, social, built, and natural capital in explaining life satisfaction at the country level: Toward a National Well-Being Index (NWI). Ecological Economics 58:119133.

[5] Engelbrecht H (2009) Natural capital, subjective well-being, and the new welfare economics of sustainability: Some evidence from cross-country regressions. Ecological Economics 69:380-388.

[6] de Vries S, Verheij RA, Groenewegen PP, Spreeuwenberg P (2003) Natural environments — healthy environments? An exploratory analysis of the relationship between greenspace and health. Environment and Planning A 35:1717-1732.

[7] Kaplan R (2001) The nature of the view from home. Environment and Behavior 33:507 -542.

[8] Brereton F, Clinch JP, Ferreira S (2008) Happiness, geography and the environment. Ecological Economics 65:386-396.

[9] Rehdanz K, Maddison D (2008) Local environmental quality and life-satisfaction in Germany. Ecological Economics 64:787-797.

[10] Maas J, et al. (2009) Morbidity is related to a green living environment. Journal of Epidemiology and Community Health 63:967-973.

[11] Berto R (2005) Exposure to restorative environments helps restore attentional capacity. Journal of Environmental Psychology 25:249-259.

[12] White M, et al. (2010) Blue space: The importance of water for preference, affect, and restorativeness ratings of natural and built scenes. Journal of Environmental Psychology 30:482-493.

[13] Ryan RM, et al. (2010) Vitalizing effects of being outdoors and in nature. Journal of Environmental Psychology 30:159-168.

[14] Hartig T, Evans GW, Jamner LD, Davis DS, Gärling T (2003) Tracking restoration in natural and urban field settings. Journal of Environmental Psychology 23:109-123.

[15] Barton J, Pretty J (2010) What is the best dose of nature and green exercise for improving mental health? A multi-study analysis. Environmental Science \& Technology 44:3947-3955.

[16] Ulrich RS (1984) View through a window may influence recovery from surgery. Science 224:420.

[17] Moore EO (1981) A prison environment's effect on health care service demands. Journal of Environmental Systems 11:17-34.

[18] Robinson MD, Clore GL (2002) Belief and feeling: Evidence for an accessibility model of emotional selfreport. Psychological Bulletin 128:934-960.

[19] Shiffman S, Stone AA, Hufford MR (2008) Ecological Momentary Assessment. Clinical Psychology 4:1-32.

[20] Hektner JM, Schmidt JA, Csíkszentmihályi M (2007) Experience Sampling Method: Measuring the Quality of Everyday Life (Sage, London).

[21] Kahneman D, Krueger AB, Schkade DA, Schwarz N, Stone AA (2004) A survey method for characterizing daily life experience: The Day Reconstruction Method. Science 306:1776-1780.

[22] Killingsworth MA, Gilbert DT (2010) A wandering mind is an unhappy mind. Science 330:932.

[23] Fuller RM, Smith GM, Sanderson JM, Hill RA, Thomson AG (2002) The UK Land Cover Map 2000: Construction of a parcel-based vector map from satellite images. The Cartographic Journal 39:15-25. 
[24] UK NEA (2010) UK National Ecosystem Assessment: progress and steps towards delivery. (United Nations Environment Programme, World Conservation Monitoring Centre (UNEP-WCMC), Cambridge, UK).

[25] House of Commons (2006) Hansard Written Answers for 18 July 2006. (London).

[26] Office for National Statistics (2010) Mid year population estimates 2009.

[27] National Centre for Social Research (2009) British Social Attitudes Survey 2009. (Economic and Social Data Service).

[28] Leamer EE (1978) Specification Searches: Ad hoc inference with nonexperimental data (John Wiley \& Sons, New York).

[29] Deaton A (1997) The analysis of household surveys: A microeconometric approach to development policy (John Hopkins University Press, for the World Bank, Baltimore).

[30] Abdi H (2007) in Encyclopedia of Measurement and Statistics (Sage, Thousand Oaks, California). 


\title{
Supplementary Information
}

\author{
Supplementary Figure
}

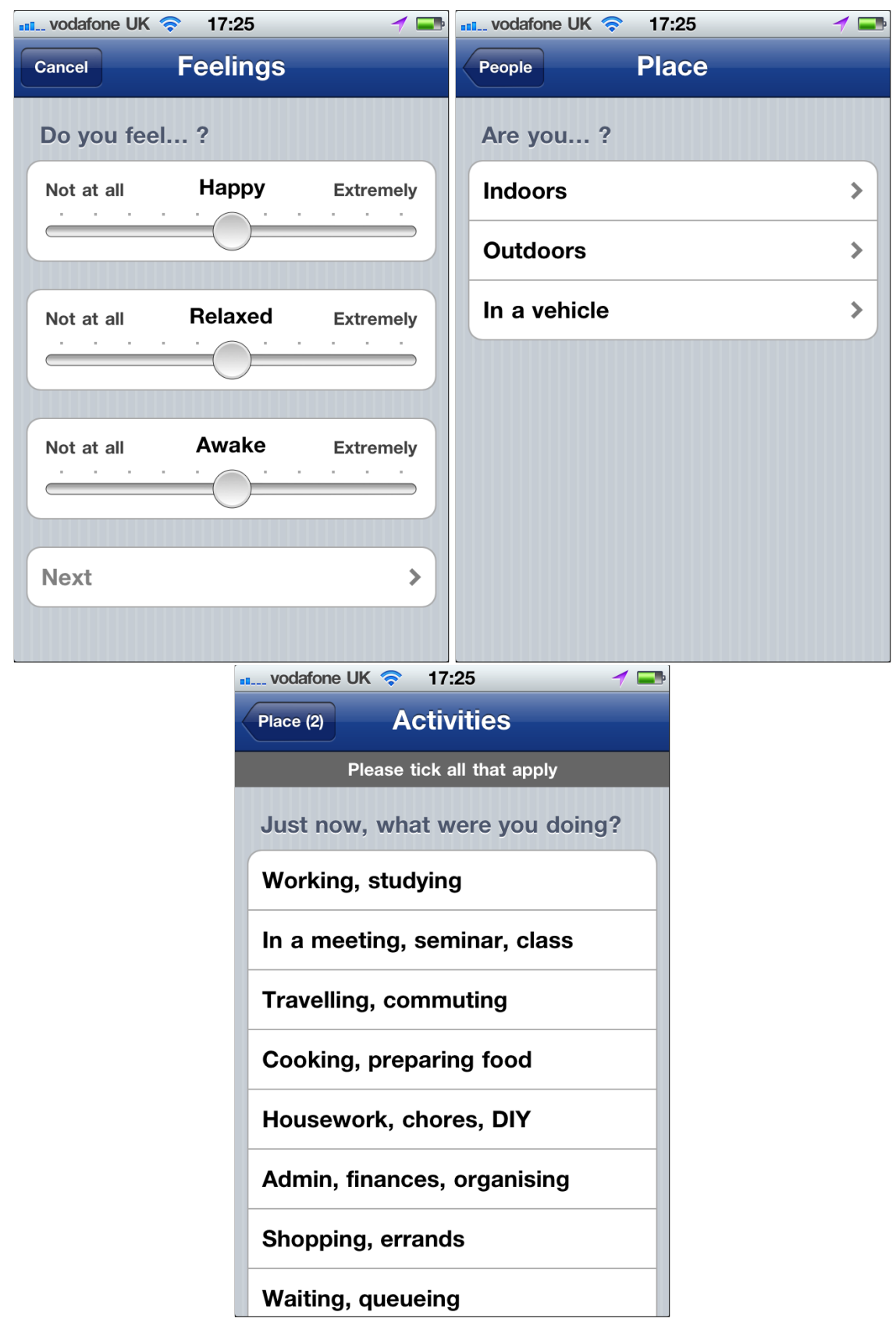

Figure S1: Example ESM questionnaire screens 


\section{Supplementary Table}

Table S1: Land Cover Map 2000 habitat category classifications

\begin{tabular}{|c|c|c|}
\hline Habitat categories & \multicolumn{2}{|c|}{ LCM level 2 subclasses } \\
\hline \multirow[t]{6}{*}{ Marine and coastal margins } & $22 \cdot 1$ & Sea/estuary \\
\hline & $20 \cdot 1$ & Littoral rock \\
\hline & $21 \cdot 1$ & Littoral sediment \\
\hline & $21 \cdot 2$ & Salt marsh \\
\hline & $18 \cdot 1$ & Supra-littoral rock \\
\hline & $19 \cdot 1$ & Supra-littoral sediment \\
\hline \multirow[t]{2}{*}{ Freshwater, wetlands and flood plains } & $13 \cdot 1$ & Water (inland) \\
\hline & $11 \cdot 1$ & Fen, marsh, swamp \\
\hline \multirow[t]{5}{*}{ Mountains, moors and heathland } & $12 \cdot 1$ & Bog \\
\hline & $10 \cdot 1$ & Dwarf shrub heath \\
\hline & $10 \cdot 2$ & Open shrub heath \\
\hline & $15 \cdot 1$ & Montane habitats \\
\hline & $9 \cdot 1$ & Bracken \\
\hline \multirow[t]{3}{*}{ Semi-natural grasslands } & $6 \cdot 1$ & Rough grass \\
\hline & $7 \cdot 1$ & Calcareous grass \\
\hline & $8 \cdot 1$ & Acid grass \\
\hline \multirow[t]{5}{*}{ Enclosed farmland } & $4 \cdot 1$ & Cereals \\
\hline & $4 \cdot 2$ & Horticulture/non-cereal or unknown \\
\hline & $4 \cdot 3$ & Not annual crop \\
\hline & $5 \cdot 1$ & Improved grassland \\
\hline & $5 \cdot 2$ & Set-aside grass \\
\hline \multirow[t]{2}{*}{ Woodland } & $2 \cdot 1$ & Coniferous woodland \\
\hline & $1 \cdot 1$ & Broad-leaved/mixed woodland \\
\hline Suburban/rural developed & $17 \cdot 1$ & Suburban/rural developed \\
\hline Continuous urban & $17 \cdot 2$ & Continuous urban \\
\hline Inland bare ground & $16 \cdot 1$ & Inland bare ground \\
\hline
\end{tabular}




\section{Supplementary Methods}

\section{ESM questionnaire}

If a signal has been received, the app launches directly into the questionnaire. The questionnaire spans multiple screens, delineated below by horizontal rules. Tapping an option suffixed by '>' immediately advances to the next screen. The first screen has a 'Cancel' button that discontinues the questionnaire, and each subsequent screen has a 'Back' button to return to the preceding screen.

THIS SCREEN IS ILLUSTRATED IN SUPPLEMENTARY FIGURE 1

\section{Feelings}

Do you feel... ?

Happy

(slider: Not at all ... Extremely)

Relaxed

(slider: Not at all ... Extremely)

Awake

(slider: Not at all ... Extremely)

Next $>$

\section{People}

Please tick all that apply

Are you...?

Alone, or with strangers only >

Or are you with your... ?

[ ] Spouse, partner, girl/boyfriend

\section{[ ] Children}

[ ] Other family members

[ ] Colleagues, classmates

[ ] Clients, customers

[ ] Friends

[ ] Other people you know

Next >

THIS SCREEN IS ILLUSTRATED IN SUPPLEMENTARY FIGURE 1

\section{Place}

Are you... ?

Indoors >

Outdoors >

In a vehicle >

Place (2)

And are you... ?

At home >

At work >

Elsewhere >

If you're working from home, please choose 'At home'

THIS SCREEN IS ILLUSTRATED IN SUPPLEMENTARY FIGURE 1

THE ACTIVITIES LIST IS ADAPTED FROM THE AMERICAN TIME USE SURVEY ACTIVITY LEXICON 2009 (US BUREAU OF LABOR STATISTICS) AND THE UNITED KINGDOM 2000 TIME USE SURVEY (UK OFFICE FOR NATIONAL STATISTICS)

\section{Activities}

Please tick all that apply

Just now, what were you doing?

[ ] Working, studying

[ ] In a meeting, seminar, class

[ ] Travelling, commuting

[ ] Cooking, preparing food

[ ] Housework, chores, DIY

[ ] Admin, finances, organising

[ ] Shopping, errands

[ ] Waiting, queueing

[ ] Childcare, playing with children

[ ] Pet care, playing with pets

[ ] Care or help for adults

[ ] Sleeping, resting, relaxing

[ ] Sick in bed

[ ] Meditating, religious activities

[ ] Washing, dressing, grooming

[ ] Intimacy, making love 
[ ] Talking, chatting, socialising

[ ] Eating, snacking

[ ] Drinking tea/coffee

[ ] Drinking alcohol

[] Smoking

[ ] Texting, email, social media

[ ] Browsing the Internet

[ ] Watching TV, film

[] Listening to music

[ ] Listening to speech/podcast

[ ] Reading

[ ] Theatre, dance, concert

[ ] Exhibition, museum, library

[ ] Match, sporting event

[ ] Walking, hiking

[ ] Sports, running, exercise

[ ] Gardening, allotment

[ ] Birdwatching, nature watching

[ ] Hunting, fishing

[ ] Computer games, iPhone games

[ ] Other games, puzzles

[] Gambling, betting

[ ] Hobbies, arts, crafts

[ ] Singing, performing

[ ] Something else

Next $>$

BY DEFAULT, THIS DIGITAL CAMERA SCREEN IS SHOWN ONLY WHEN OUTDOORS

Please take a photo straight ahead

Or tap Cancel to skip this step

THIS SCREEN IS SHOWN ONLY IF A PHOTO WAS TAKEN

Map

Add this photo to the public map?

Yes $>$

No $>$
THIS SCREEN IS SHOWN ONLY WHEN OUTDOORS AND IN THE RARE EVENT THAT GPS LOCATION ACCURACY IS STILL WORSE THAN 100M. IT ADVANCES AUTOMATICALLY WHEN ACCURACY REACHES 100M OR 60 SECONDS HAS ELAPSED.

\section{Location}

Improving location accuracy

Skip >

THE QUESTIONNAIRE DISMISSES ITSELF IMMEDIATELY AFTER THIS SCREEN IS DISPLAYED

\section{Finished}

Thank you! 